\title{
Coagulation profile of Sudanese children with homozygous sickle cell disease and the effect of treatment with omega-3 fatty acid on the coagulation parameters
}

\author{
Shiekh Awoda ${ }^{1,3}$, Ahmed A. Daak ${ }^{1,2,4^{*}}$ (D), Nazik Elmalaika Husain ${ }^{3}$, Kebreab Ghebremeskel ${ }^{4}$ and Mustafa I. Elbashir ${ }^{1}$
}

\begin{abstract}
Background: It has been reported that patients with SCD do have an abnormal coagulation profile. Coagulopathy is thought to be one of the key factors that contribute to the vaso-occlusive crisis that characterises sickle cell disease (SCD). In this study, we investigated whether Sudanese sickle cell patients have an abnormal coagulation profile. In addition, the effect of treatment with either omega-3 fatty acids or hydroxyurea on coagulation profile was assessed.
\end{abstract}

Methods: Homozygous SCD patients untreated $(n=52)$, omega-3 treated $(n=44)$, hydroxyurea $(H U)$ treated $(n=8)$ and healthy (HbAA) controls $(n=52)$ matched for age (4-20 years), gender and socioeconomic status were enrolled. Patients on omega-3 fatty acids, according to age, received one to four capsules containing 277. $8 \mathrm{mg} \mathrm{DHA}$ and $39.0 \mathrm{mg}$ eicosapentnoic. Patients on Hydroxyurea were in on dosage more than $20 \mathrm{mg} / \mathrm{kg} / \mathrm{day}$. The steady state levels of the coagulation parameters and the effect of the treatments with either HU or omega-3 fatty acids on markers of coagulation were investigated.

Results: Compared to the healthy controls, treated and untreated HbSS patients had lower hemoglobin, plasma Protein C, proteins S and higher white blood cell count (WBC), platelets count (PLTs) and plasma D-dimer levels, $(p<0.05)$. In comparison to untreated HbSS, treatment with neither omega-3 nor HU had effect on the WBC, plasma proteins $C$ and $S,(p>0.05)$. HU treated group had a lower PLTs count compared to HbSS untreated group $(p<0.5)$. The prothrombin and activated partial thromboplastin times and international normalized ratio (INR) of untreated patients are significantly higher than n-3 treated, HU-treated patients and health controls, $(p<0.05)$. Patients treated with omega-3 had lowered D-dimer levels in comparison to HU-treated and untreated HbSS patients, $(p<0.001)$.

Conclusion: This study provides evidence that Sudanes patients have abnormal coagulation profile and treatment with either HU or omega-3 fatty acids might partially ameliorate SCD-associated chronic coagulopathic state.

Keywords: Sickle cell disease, Coagulation, Omega-3 fatty acids, D-dimer, Protein C, Protein S

\footnotetext{
*Correspondence: ahmed.malik@meduofk.net; malikdaak@hotmail.com ${ }^{1}$ Department of Medical Biochemistry, Faculty of Medicine, University of Khartoum, Alghasr Street, Khartoum, Sudan

${ }^{2}$ Center of Molecular Biology and Biotechnology (CMBB), Florida Atlantic University (FAU), Boca Raton, USA

Full list of author information is available at the end of the article
} 


\section{Background}

Chronic hypercoagulable or prothrombotic state is generally known to be one of the factors that contribute to vaso-occlusion and progressive end-organ damage in sickle cell disease (SCD) $[1,2]$. Studies on SCD patients at steady state patients from different geographic and demographic origins have shown elevated level of markers of coagulation activation [3, 4], and decreased natural anticoagulant proteins [5, 6]. Agents that physiologically activate platelets and coagulation in vivo include adenosine diphosphate (ADP), collagen, epinephrine, thrombin, serotonin, arachidonic acid and thromboxane A2 [7]. Interestingly, blood cell membranes of patients with SCD have an abnormal fatty acid profile which is characterised by low levels of omega-3, namely eicosapentaenoic (EPA) and docosahexaenoic acids (DHA), and a high level of omega-6, particularly arachidonic acid (AA) [8,9]. A high intake of omega-3 fatty acids is inversely associated with thromboxane level and prothrombotic activity $[10,11]$. Consequently, it has been postulated that regular intake of n-3 fatty acids in patients with SCD may modulate markers of coagulation.

On the other hand, Hydroxyurea (hydroxycarbamide) is currently the only approved drug to prevent the acute complications of the disease [12], and has several welldefined beneficial effects that might involve mitigation of the hypercoagulability state in patients with SCD [13]. In this study we investigated whether (1) Sudanese sickle cell patients have an abnormal profile of coagulation parameters; (2) the coagulation parameter are modified by omega-3 fatty acids or hydroxyurea.

\section{Methods}

\section{Subjects}

In this study, steady state homozygous sickle cell patients (HbSS) on high DHA omega-3 treatment $(n=44)$, hydroxyurea treatment $\mathrm{HbSS}$ (HU, $n=8$ ), steady $\mathrm{HbSS}$ patients not treated either with $\mathrm{HU}$ or omega-3 fatty acids $(n=52)$ controls and healthy sibling controls (HbAA, $n=52)$, matched one to one by age (4-20 years), gender and socioeconomic status were included. "Steady state" is defined as being free from acute painful crisis or other medical condition for at least one month before the enrolment. The patients and healthy controls, who were mostly siblings of the patients, were enrolled from Abnaof Paediatric Hospital, Khartoum, Sudan, between February and May 2014. We selected the patients' healthy HbAA siblings as controls in order to minimise the potential effect of dietary background and genetic factors on the variables under investigation. Haemoglobin phenotypes were confirmed using cellulose acetate electrophoresis at $\mathrm{pH}$ 8.5. The exclusion criteria for participation in the study were other chronic disorder and conditions (defined as the one that lasting 3 months or more), blood transfusion in the previous four-months. The patients on $n-3$ fatty acids received a daily dosage of one, two, three or four capsules according to the patient's age $(<5),(5-10),(11-16)$ and $(>17)$ years, respectively. The n-3 capsule contains $277.8 \mathrm{mg}$ docosahexaenoic (DHA) and $39.0 \mathrm{mg}$ eicosapentnoic (EPA) and $(1.5 \mathrm{mg})$ of vitamin $\mathrm{E}$ to prevent fatty acids peroxidation. The $\mathrm{n}-3$ fatty acid group was on same dosage of n-3 fatty acids for minimum of three years. The hydroxyurea group was treated daily with a dose of $20 \mathrm{mg}$ per kilogram body weight orally for minimum of at least one year. The patients participated in this study were on regular folate supplement. The healthy control subjects did not receive folate or any other nutritional supplement.

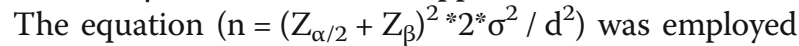
to calculate the sample size, and the assumption that the mean difference of D-dimer between the omega-3 treated and untreated patients $1 \mu \mathrm{g} / \mathrm{ml}$ compared to untreated. The population variance was assumed to equal to $2 \mu \mathrm{g} / \mathrm{ml}$. To detect the assumed mean difference with $95 \%$ power at a $5 \%$ significance level, minimum of 43 patients is required in each arm.

\section{Blood sample collection and processing}

Blood was drawn under sterile conditions into EDTA coated $(2.5 \mathrm{ml})$ and tri-sodium citrate $(2.5 \mathrm{ml})$ containing vacutainer tubes. The EDTA blood was used for hematological tests. The citrate blood was immediately fractionated into plasma and red blood cells by cold centrifugation at $3000 \mathrm{rpm}$ for $15 \mathrm{~min}$. The resulting top plasma layer was carefully siphoned off, without contaminating with buffy coat, and transferred into another tube and stored at $-80{ }^{\circ} \mathrm{C}$. The stored plasma was subsequently used for the determination of coagulation profile and anticoagulation proteins.

\section{Hematological parameters}

Haemoglobin concentration $(\mathrm{Hb})$, haematocrit $(\mathrm{Ht})$, mean corpuscular volume (MCV), mean corpuscular haemoglobin $(\mathrm{MCH})$, mean corpuscular haemoglobin concentration (MCHC), total white blood cell count (TWBC), platelet count (PLTs) and total red blood cell count were measured with the use of Sysmex KX-21 N Automated Hematology Analyzer (Sysmex Corporation, Kobe, Japan).

\section{Coagulation profile}

Prothrombin time (PT) and activated partial thromboplastin time (aPTT) were determined by an automated micro-computer controlled coagulometer, DiaMed-CD2 (DIaMed, GmbH, Cressier, Switzerland). International normalized ratio (INR) was also assessed. 


\section{D-dimer}

The concentration of D-dimer was measured by enzymelinked immune-sorbent assay using i-Chroma hsCRP test kits and i-CHROMA Reader (BodiTech Med Inc., Gang-won do, Korea).

\section{Anticoagulation proteins $\mathrm{C}$ and $\mathrm{S}$}

Proteins $\mathrm{C}$ and $\mathrm{S}$ concentrations were determined by enzyme linked immune-sorbent assay kit (Asys Hitech $\mathrm{GmbH}$, Austria).

\section{Data analysis}

According to the parametric or non-parametric distribution, the data were expressed as mean \pm SD or median and interquartile range (IQR) as pertinent. The groups were compared for haematological profile, coagulation profile, anticoagulant proteins and D-dimer levels by using one-way an ANOVA on ranks (Kruskal-Wallis $\mathrm{H}$ test). When statistical differences were indicated, Dunn's non-parametric comparison for post-hoc tests were obtained. The statistical significance was assumed at a "p" value of less than 0.05 . The data were analysed with SPSS for Windows, Version 19 (SPSS Ltd., Surrey, UK).

\section{Results}

\section{Demographic and haematological characteristics}

The baseline demographic and haematological values of the omega-3 fatty acid treated and untreated patients and healthy controls were described in Table 1 . The mean age of the patients on $\mathrm{HU}$ was significantly higher than that of the other three groups $(p<0.05)$.

\section{Haematological parameters}

The hematological values of the groups studied were shown in Table 2. Apart from PLT count, neither treatment with omega-3 nor HU resulted in significant change in haematological profile in comparison to $\mathrm{HbSS}$ untreated patients. The haematological parameters $\mathrm{MCV}, \mathrm{MCH}$ and $\mathrm{MCHC}$ values of the patients and healthy controls were not different $(p>0.05)$.

Table 1 Baseline demographic and hematological characteristics of the patients and healthy controls

\begin{tabular}{|c|c|c|c|c|}
\hline & $\begin{array}{l}\text { HbSS Omega }-3 \\
\text { treated }\end{array}$ & $\begin{array}{l}\text { HbSS Omega -3 } \\
\text { untreated }\end{array}$ & $\begin{array}{l}\text { HbSS HU- } \\
\text { treated }\end{array}$ & $\begin{array}{l}\text { HbAA } \\
\text { Healthy } \\
\text { controls }\end{array}$ \\
\hline $\begin{array}{l}\text { Number of } \\
\text { patients }(n)\end{array}$ & 44 & 52 & 8 & 52 \\
\hline Male & 22 & 28 & 6 & 28 \\
\hline Female & 22 & 24 & 2 & 24 \\
\hline $\begin{array}{l}\text { Age (years, } \\
\text { mean } \pm \text { SD) }\end{array}$ & $9.8 \pm 2.9$ & $10.8 \pm 4.0$ & $17.4 \pm 0.9^{*}$ & $11.3 \pm 4.0$ \\
\hline
\end{tabular}

\section{Coagulation profile (PT, aPTT and INR)}

In comparison with the healthy controls, the omega-3 fatty acid treated, HU-treated and untreated patients had increased PT, aPTT and INR ( $p<0.01$, Table 3$)$. The omega-3 treated and, HU-treated patients had significantly lower coagulation parameters when compared with Untreated patients $(p<0.05$, Table 3$)$.

\section{Plasma D-dimer levels}

The healthy control subjects had a lower level of plasma D-dimer concentration than the omega-3 fatty acid treated, HU-treated and un-treated patients $(p<0.001)$. The omega-3 fatty acid treated group compared with HU-treated (Median = 1.14 $(\mathrm{IQR}=0.74)$ $\mu \mathrm{g} / \mathrm{ml}$ vs Median $=2.33 .0(\mathrm{IQR}=3.17) \mu \mathrm{g} / \mathrm{ml}$, $(p<0.001))$ and untreated (Median $=1.4(\mathrm{IQR}=0.74)$ $\mu \mathrm{g} / \mathrm{L}$ vs Median = $1.75(\mathrm{IQR}=1.16) \mu \mathrm{g} / \mathrm{ml},(p<0.001)$ patients had a lower plasma D-dimer level. Patients treated with HU had a higher levels of plasma D-dimer compared to HbSS untreated ( $p<0.01$, Fig. 1$)$.

\section{Plasma proteins $\mathrm{C}$ and S levels}

The untreated patients had reduced level of plasma protein $\mathrm{C}$ compared with the healthy controls (Median $=90.5$ $(\mathrm{IQR}=20.0) \mu \mathrm{g} / \mathrm{mL},(p<0.001)$. The omega-3 fatty acid $($ Median $=60.5(\mathrm{IQR}=19) \mu \mathrm{g} / \mathrm{mL})$ and $\mathrm{HU}($ Median $=59.5$ $(\mathrm{IQR}=13) \mu \mathrm{g} / \mathrm{mL}),(p>0.05)$ treated and the untreated $($ Median $=60.0(\mathrm{IQR}=23.0) \mu \mathrm{g} / \mathrm{mL})$ patients had comparable concentration of protein $C(p>0.05$, Fig. 2$)$.

Plasma protein $\mathrm{S}$ concentration was lower in the treated (omega- 3 and $\mathrm{HU}$ ) and untreated patients than in the healthy controls (Median $=139.5(\mathrm{IQR}=28.0)$ $\mu \mathrm{g} / \mathrm{mL},(p<0.001))$. There was no difference in protein $\mathrm{S}$ level between the unntreated (Median $=42.5$ $(\mathrm{IQR}=18.0) \mu \mathrm{g} / \mathrm{mL})$, omega-3 treated $($ Median $=45.5$ $(\mathrm{IQR}=14.0) \mu \mathrm{g} / \mathrm{mL})$ and HU-treated (Median $=40.5$ $(\mathrm{IQR}=11) \mu \mathrm{g} / \mathrm{mL})$ patients $(p>0.05$, Fig. 3$)$.

\section{Discussion}

Hydroxyurea, which is a cytotoxic, antimetabolic and antineoplastic agent, is the only disease-modifying therapy approved for sickle cell disease [14]. Hydroxyurea has been shown to be partially effective in reducing the frequency of vaso-occlusive events; but, there is no evidence that it prevents organ damage [15]. One of the factors which restricts HU usage is that it undergoes renal clearance, and hence there is a need for careful dose adjustment and close monitoring of myelotoxicity in individuals with renal impairment [16]. This vital requirement is hardly possible to undertake in most developing countries where SCD is highly prevalent because of lack of functional facilities and expertise. Therefore, there is a need for safe, effective and easily manageable treatment(s) for children and adult patients with sickle cell disease. Clinical trials have provided 
Table 2 Mean ( \pm sd) hematological parameter values of omega-3 fatty acid treated, hydroxyurea treated and untreated patients (HbSS) and healthy controls

\begin{tabular}{lllll}
\hline & Omega-3 FA Treated Patients & Untreated patients & HU Treated & Healthy Controls \\
\hline $\mathrm{Hb}(\mathrm{g} / \mathrm{l})$ & $75.6 \pm 16.2^{* * *}$ & $75.9 \pm 10.3^{+++}$ & $79.5 \pm 10.3$ & $126.0 \pm 10.9$ \\
$\mathrm{HCt}$ & $22.9 \pm 4.7^{* * *}$ & $22.9 \pm 3.0^{+++}$ & $23.8 \pm 2.8$ & $38.0 \pm 3.5$ \\
$\mathrm{RBC}$ & $2.8 \pm 0.7^{* * *}$ & $2.7 \pm 0.5^{+++}$ & $2.8 \pm 0.6$ & $4.6 \pm 0.5$ \\
$\mathrm{MCV}(\mathrm{fl})$ & $84.3 \pm 8.6$ & $86.5 \pm 7.1$ & $87.8 \pm 11.6$ & $82.3 \pm 4.7$ \\
$\mathrm{MCH}(\mathrm{pg})$ & $27.9 \pm 3.4$ & $28.6 \pm 3.0$ & $29.5 \pm 4.4$ & $27.6 \pm 1.9$ \\
$\mathrm{MCHC}$ & $33.3 \pm 2.0$ & $33.1 \pm 1.4$ & $33.4 \pm 0.9$ & $33.5 \pm 1.5$ \\
$\mathrm{PLT}$ & $489.5 \pm 121.1^{* * *}$ & $533.6 \pm 98.7^{+++}$ & $414.5 \pm 109.9^{\times}$ & $330.3 \pm 72.5$ \\
WBC & $12.4 \pm 4.3^{* * *}$ & $13.3 \pm 3.4^{+++}$ & $13.6 \pm 3.7$ & $6.3 \pm 1.3$ \\
\hline
\end{tabular}

${ }^{* * *} p<0.001$ Omega 3 treated versus healthy controls

$++p<0.01,+++p<0.001$ Untreated patients versus healthy controls

${ }^{\mathrm{x}} p<0.05$, HU treated versus untreated patients

evidence that omega-3 fatty acids are effective in reducing frequency and severity of vaso-occlusive episodes, severe anemia, blood transfusion rate, markers of inflammation and oxidative stress [17-21]. In the current study, patients treated with omega-3 showed a significant reduction in Ddimer. The findings of this study indicate that treatment with omega-3 may partially ameliorate SCD-associated coagulopathy.

The SCD patients and healthy controls who participated in this study were homogenous with respect to ethnicity and socio-economic background and the patients received similar quality of care under regular management protocols. The samples were collected in one clinic and at the same time of the year. Therefore, the observed findings are likely to be due to the effect of intervention with omega-3 fatty acids or hydroxyurea treatment rather than of extraneous confounding factors.

Consistent with previous studies, both the omega- 3 fatty acid treated and untreated patients had elevated steady state white blood cell and platelet counts confirming that sickle cell disease is a chronic inflammatory disorder [22]. Similarly, Tomer et al. [18] have reported that treatment with omega-3 fatty acids do not effect significantly the blood cell count, MCV or MCHC.

There is evidence which indicates that HU mediates its beneficial effects in SCD, partially, by lowering leukocyte, reticulocyte and platelet counts [23]. In the current study,

Table 3 Mean ( \pm sd) coagulation profile parameter values of omega-3 fatty acid and hydroxyurea treated and untreated sickle cell patients (HbSS) and healthy contols

\begin{tabular}{lllll}
\hline & Omga-3 treated & untreated & HU treated & Healthy controls \\
\hline PT (sec) & $17.2 \pm 1.8^{t++}$ & $31.3 \pm 11.1^{+++}$ & $18.2 \pm 1.8^{\times x x}$ & $14.5 \pm 0.7$ \\
aPTT (sec) & $38.3 \pm 4.2^{t++}$ & $57.0 \pm 11.3^{+++}$ & $42.8 \pm 2.7^{\times x x}$ & $37.0 \pm 3.8$ \\
INR & $1.2 \pm 0.14^{t++}$ & $2.3 \pm 0.90^{+++}$ & $1.3 \pm 0.12^{x \times x}$ & $1.01 \pm 0.05$ \\
\hline
\end{tabular}

$++\dagger p<0.001$ omega-3 treated versus untreated patients

${ }^{+++} p<0.001$ untreated patients versus healthy controls

${ }^{\mathrm{xx}_{p}} p<0.001 \mathrm{HU}$ treated versus untreated patients
HU treatment reduced platelet count significantly but had no noticeable effect on WBC. This unexpected effect of HU on WBC among Sudanese children with SCD might be a reflection of the fact that $\mathrm{HU}$ is generally being administered mostly to the severely ill children with SCD [24], or a response peculiar to Sudanese SCD patients that warrant further research.

The PT, aPTT and INR levels of the untreated patients were significantly higher than the n-3 fatty acid and hydroxyurea treated groups. Similar findings have been observed on Americans [25] and Nigerians children [26] and adult Jamaicans [6] with sickle cell disease. The prolongation of $\mathrm{PT}$ in the adult patients was not as remarkable as in the children. In contrast, another study investigated 17 subjects did not find a difference in mean PT between SCD and healthy children [27]. These controversial findings might be a reflection of the study small sample size.

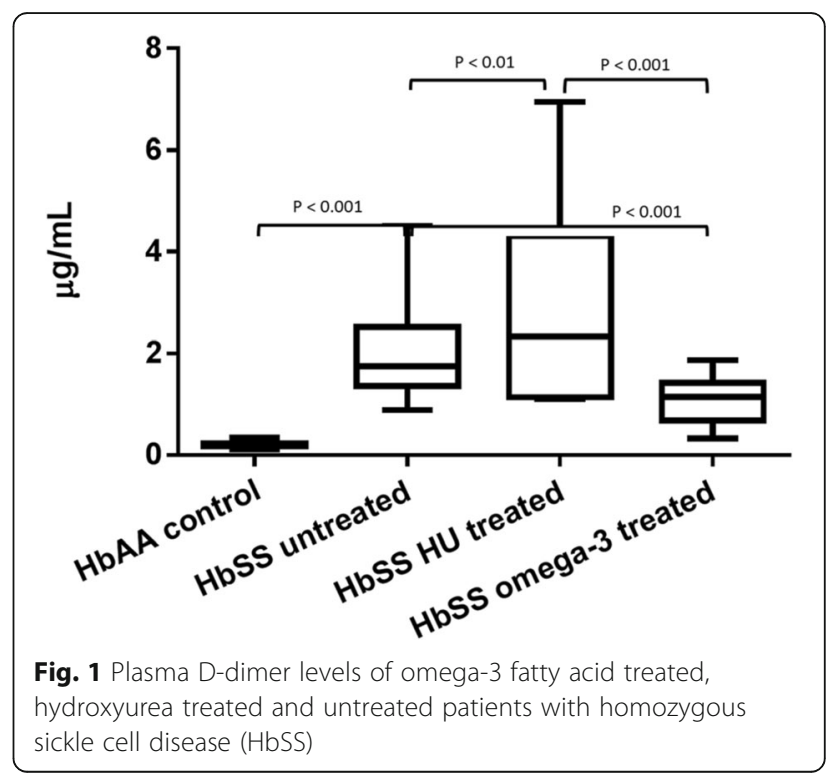




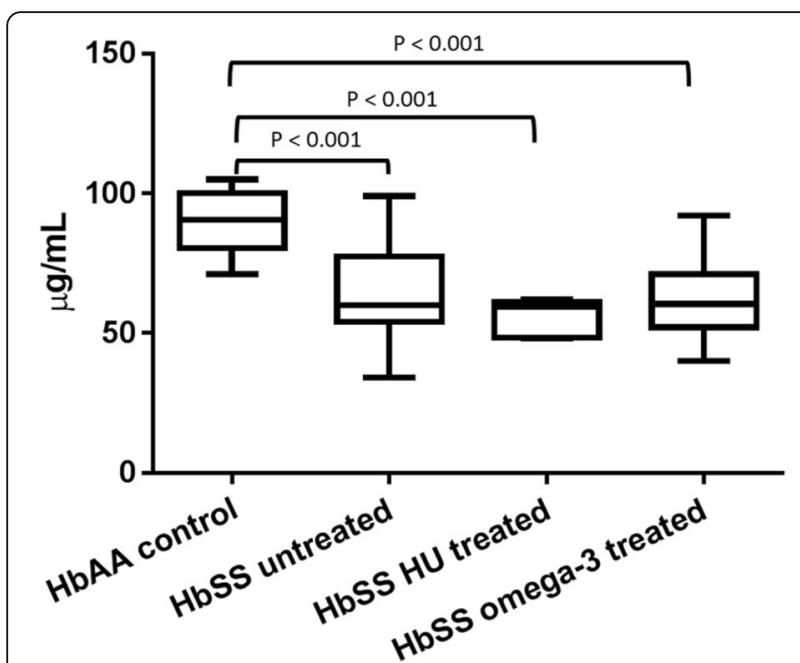

Fig. 2 Plasma Protein C levels of omega-3 fatty acid treated, hydroxyurea treated and untreated patients with homozygous sickle cell disease (HbSS). *There were no significant differences $(p>0.05)$ between the HbSS untreated, HbSS HU treated and HbSS omega-3 treated

The mechanism behind the prolongation of PT in children with SCD is not fully understood. It is suggested that impaired liver function [25] and depletion of coagulation factors [28] play a role in the prolongation process. However, it is worth pointing out that a relationship between an abnormal liver function and coagulation prolongation is yet to be established.

In contrast to the findings of the current study, high omega-3 fatty acid intake did not have a significant effect on PT and aPTT in adult patients with sickle cell disease

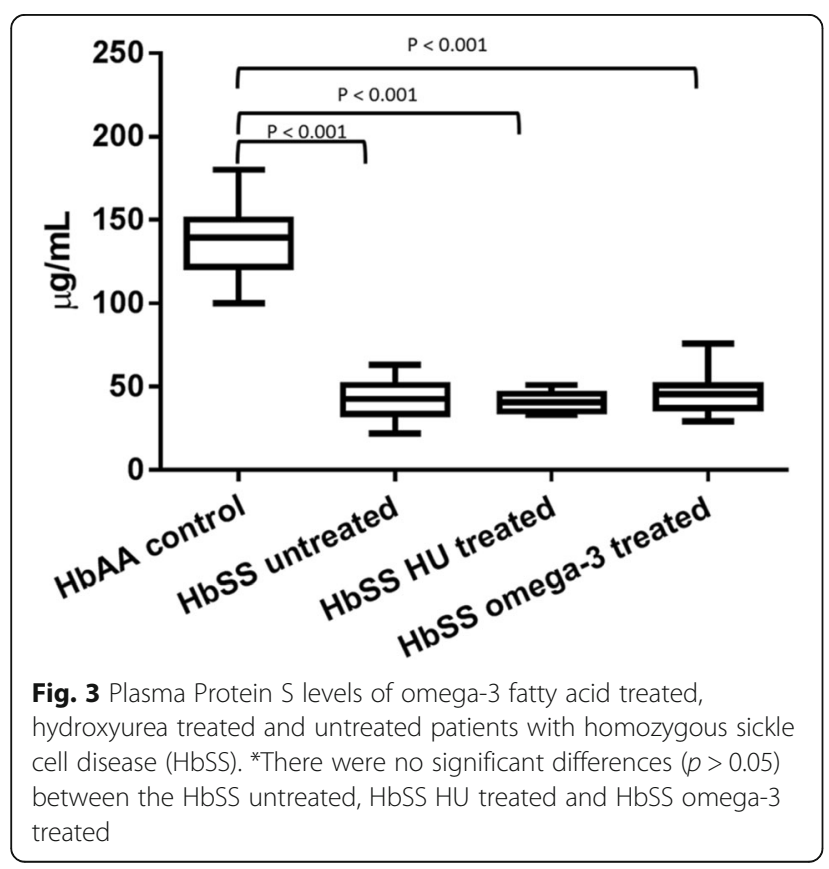

[18], and in adult carcinoma patients undergoing elective surgery [29]. The subjects in the latter two studies, $[18,29]$, were adults from different ethnic background clinical complications and normal coagulation parameter values at baseline. In addition, the $\mathrm{n}-3$ fatty acids composition of the oil/supplement used in these two studies were different from the high DHA capsules given to the children in the current study. The observed reduction of coagulation parameters in treated SCD patients in this study could be the result of increased availability of the coagulation factors and the possible concomitant reduction in coagulation activation that could surpass its potential detrimental hypo-coagulant effect [30, 31]. HU treatment had a similar effect as n-3 fatty acids on PT and aPTT suggesting that children with abnormal coagulation profile are responsive to either therapy.

The low level steady-state proteins $\mathrm{C}$ and $\mathrm{S}$ in the Sudanese children with SCD, which agrees with previous findings $[6,32]$, is in line with the hypothesis that the chronic activation of both the inflammatory and coagulant pathways in SCD are partially due to the disease associated down regulation of anti-coagulant pathway [33]. Protein C, activated by thrombin in the presence of protein $\mathrm{S}$, inhibits the clotting ability of factor $\mathrm{V}$ and VIII [34]. The underlying cause of the natural anticoagulant deficiency is yet to be elucidated. However, it has been generally attributed to the known SCDassociated hemostatic abnormalities and hepatic dysfunction [27]. An earlier study [35] reported a decrease in proteins $C$ in children with sickle cell disease treated with hydroxyurea. That study included 11 children, 5 of them were homozygous SCD patients. The discrepancy of $\mathrm{HU}$ effect on proteins $\mathrm{C}$ and $\mathrm{S}$ between this study and the previous study could be due to the fact that Koc et al. study [35] was relatively underpowered to detect the true $\mathrm{HU}$ effect on natural anti-coagulant system.

Despite the observed improvement in coagulation parameters and hypercoagulable state, treatment with n-3 fatty acids did not result in a significant change on the level of the natural anti-coagulant proteins $\mathrm{C}$ and $\mathrm{S}$. These findings may indicate that the liver role on low natural anticoagulant in SCD might outweigh the effect of over-consumption due to SCD-associated hypercoagulable state.

The high levels of D-dimer in patients in the current study confirm that hypercoagulability state is one of the major elements of pathophysiology of the disease [33, 36]. Previous studies have reported that omega- 3 fatty acid intake is inversely associated with the level of fibrinogen, factor VIII and von Willebrand factor (VWF) [37] and D-dimer [18]. Consistent with the latter study, the current investigation demonstrates high DHA omega-3 fatty acid, but not $\mathrm{HU}$, treatment reduces plasma $\mathrm{D}$-dimer 
concentration in patients with SCD. The decrease of Ddimer by omega- 3 fatty acids has implications for clinical management of patients because plasma D-dimer level is associated with a history of stroke in SCD [36].

This study did not attempt to elucidate the mechanism through which omega-3 fatty acids, particularly DHA and EPA, mediate their anti-coagulant effect. Nevertheless, it is well established that some of the metabolites of these fatty acid are antithrombotic, antiaggregatory, antiinfalammrory and vasodilatory. EPA by competing with arachidonic acid (AA) for cyclooxygenase and lipooxygenase enzymes [38] inhibits the synthesis of the prothrombotic proaggregatory, pro-inflammatory and vasoconstrictor metabolites of AA. Recent animal and human studies suggest that DHA is more potent anti-aggregatory agent than EPA at high doses [39-41]. Interestingly, studies in SCD have demonstrated that endothelial tissue factor expression is specifically dependent upon the nuclear factor-kappa B (NFkB) component of blood mononuclear cells [42]. Our group and others have shown that treatment with high DHA omega-3 fatty acid was associated with down regulation of NFKB gene expression in mononuclear cell and amelioration of SCDassociated chronic inflammatory state [20,43]. Hence, it is justifiable to attribute the observed improvements in the patient's hypercoagulable state after high DHA intervention to its suppressive effect on NFKB gene expression and partial resolution of the chronic inflammatory state [44].

Besides the limitations of the observational studies, the current study did not assess liver function in order to have a better understanding of the observed abnormalities of coagulation system and the responses to $\mathrm{HU}$ and omega-3 treatments. In addition, the effect of omega-3 fatty acids and HU treatments on markers of thrombin generation such as prothrombin fragment F1, 2 and thrombin-anti-thrombin complexes, was not investigated. Due to the fact that only patients above 10 years of age are treated with $\mathrm{HU}$ and generally small fraction of patients were treated with $\mathrm{HU}$ in Sudan, we did not manage to recruit enough number of patients on $\mathrm{HU}$ matched by age and gender.

\section{Conclusion}

In conclusion, this study provides an evidence that Sudanese children with sickle cell disease have an abnormal coagulating profile which characterized by prolonged PT and aPTT compared to heathy controls. These two parameters were significantly reduced by treatment with either HU or omega-3 fatty acids. With the exception of the D-dimer, treatment with neither omega-3 fatty acids nor HU resulted in a significant change in markers of coagulation compared to the untreated group. To elucidate the putative effects of omega-3 fatty acids on SCD-associated coagulopathy, a well-designed, prospective, randomized trial with an extended panel of hemostaticis is warranted.

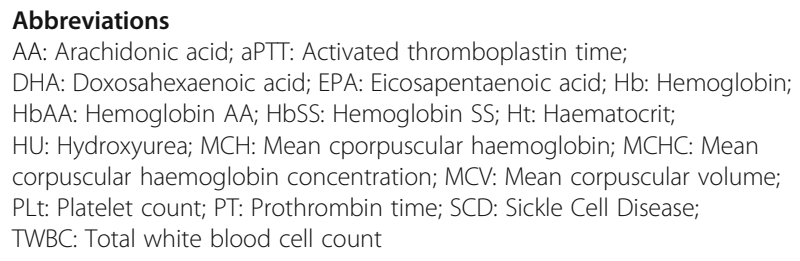

\section{Acknowledgements}

We are grateful to Dr. Bakhita Attallah who established the Sickle Cell Referral Clinic in Ibn-Aoaf Paediatric Hospital, Khartoum and devoted her professional life caring for the patients with the disease. Particular thanks go to the to the staff of the Sickle Cell Disease Referral Clinic, and Khartoum Teaching Hospitals (Sudan), and to Peter Clough, Efamol Limited UK, for his expert advice on the selection of the supplements used and for support throughout the duration of this study.

\section{Funding}

Efamol Lt, UK and Faculty of Medicine University of Khartoum.

\section{Availability of data and materials}

All data on which the conclusions of this manuscript are drawn are contained in the main manuscript and tables herein.

\section{Authors' contributions}

AD conceptualized, designed the study and wrote the manuscript. SA collated the data and performed the laboratory analysis. AD and SA conducted the statistical analysis. ME and SA contributed to writing the manuscript. ME, NH and KG contributed to reviewing the manuscript. All authors approved the final version of the manuscript.

\section{Ethical approval and consent to participate}

Ethical approval was obtained from the Research Board and Ethics Committee of the Faculty of Medicine, University of Khartoum, Sudan. Written informed consent to patriciate and publish the study results was obtained from all patients or guardians before being included in the study. Privacy and confidentiality was maintained at each step of the study process.

Consent for publication

Not applicable.

\section{Competing interests}

The funding bodies (Efamol Limited UK and University of Khartoum) had no influence on the study design, collection and analysis of data, interpretation of results or writing. The authors declare that they have no competing interests.

\section{Publisher's Note}

Springer Nature remains neutral with regard to jurisdictional claims in published maps and institutional affiliations.

\section{Author details}

'Department of Medical Biochemistry, Faculty of Medicine, University of Khartoum, Alghasr Street, Khartoum, Sudan. ${ }^{2}$ Center of Molecular Biology and Biotechnology (CMBB), Florida Atlantic University (FAU), Boca Raton, USA. ${ }^{3}$ College of Medical Laboratory Sciences, Sudan University of Science\& Technology, Khartoum, Sudan. ${ }^{4}$ Lipidomics and Nutrition Research Centre, London Metropolitan University, London, UK.

Received: 20 July 2017 Accepted: 19 September 2017

Published online: 09 November 2017

\section{References}

1. Stuart MJ, Setty BN. Hemostatic alterations in sickle cell disease: relationships to disease pathophysiology. Pediatr Pathol Mol Med. 2001;20(1):27-46. 
2. Ataga Kl, Orringer EP. Hypercoagulability in sickle cell disease: a curious paradox. Am J Med. 2003;115(9):721-8.

3. Tomer A, et al. Thrombogenesis in sickle cell disease. J Lab Clin Med. 2001;137(6):398-407.

4. Francis RB Jr. Elevated fibrin D-dimer fragment in sickle cell anemia: evidence for activation of coagulation during the steady state as well as in painful crisis. Haemostasis. 1989;19(2):105-11.

5. Westerman MP, et al. Antiphospholipid antibodies, proteins $C$ and $S$, and coagulation changes in sickle cell disease. J Lab Clin Med. 1999;134(4):352-62.

6. Wright JG, et al. Protein $\mathrm{C}$ and protein $\mathrm{S}$ in homozygous sickle cell disease: does hepatic dysfunction contribute to low levels? Br J Haematol. 1997; 98(3):627-31.

7. Zhou L, Schmaier AH. Platelet aggregation testing in platelet-rich plasma: description of procedures with the aim to develop standards in the field. Am J Clin Pathol. 2005;123(2):172-83.

8. Connor WE, et al. Abnormal phospholipid molecular species of erythrocytes in sickle cell anemia. J Lipid Res. 1997;38(12):2516-28.

9. Ren $\mathrm{H}$, et al. Blood mononuclear cells and platelets have abnormal fatty acid composition in homozygous sickle cell disease. Ann Hematol. 2005; 84(9):578-83.

10. Singer P, Wirth M. Can n-3 PUFA reduce cardiac arrhythmias? Results of a clinical trial. Prostaglandins Leukot Essent Fatty Acids. 2004;71(3):153-9.

11. Gao LG, et al. Influence of omega-3 polyunsaturated fatty acidsupplementation on platelet aggregation in humans: a meta-analysis of randomized controlled trials. Atherosclerosis. 2013;226(2):328-34.

12. Steinberg $M H$, et al. Effect of hydroxyurea on mortality and morbidity in adult sickle cell anemia: risks and benefits up to 9 years of treatment. JAMA. 2003:289(13):1645-51.

13. Colella MP, et al. Hydroxyurea is associated with reductions in hypercoagulability markers in sickle cell anemia. J Thromb Haemost. 2012; 10(9):1967-70

14. McGann PT, Ware RE. Hydroxyurea for sickle cell anemia: what have we learned and what questions still remain? Curr Opin Hematol. 2011;18(3): 158-65

15. Wang WC, et al. Hydroxycarbamide in very young children with sickle-cell anaemia: a multicentre, randomised, controlled trial (BABY HUG). Lancet. 2011;377(9778):1663-72.

16. Yan $\mathrm{JH}$, et al. The influence of renal function on hydroxyurea pharmacokinetics in adults with sickle cell disease. J Clin Pharmacol. 2005; 45(4):434-45.

17. Daak AA, et al. Effect of omega-3 (n-3) fatty acid supplementation in patients with sickle cell anemia: randomized, double-blind, placebocontrolled trial. Am J Clin Nutr. 2012;97(1):37-44.

18. Tomer A, et al. Reduction of pain episodes and prothrombotic activity in sickle cell disease by dietary n-3 fatty acids. Thromb Haemost. 2001;85(6): 966-74.

19. Daak AA, et al. Docosahexaenoic and eicosapentaenoic acid supplementation does not exacerbate oxidative stress or intravascular haemolysis in homozygous sickle cell patients. Prostaglandins Leukot Essent Fatty Acids. 2013;89(5):305-11.

20. Daak $A A$, et al. Omega 3 (n-3) fatty acids down-regulate nuclear factorkappa B (NF-kappaB) gene and blood cell adhesion molecule expression in patients with homozygous sickle cell disease. Blood Cells Mol Dis. 2015; 55(1):48-55

21. Okpala I, et al. Pilot study of omega-3 fatty acid supplements in sickle cell disease. APMIS. 2011;119(7):442-8.

22. Curtis SA, et al. Elevated steady state WBC and platelet counts are associated with frequent emergency room use in adults with sickle cell anemia. PLoS One. 2015;10(8):e0133116.

23. Ballas SK, et al. Erythropoietic activity in patients with sickle cell anaemia before and after treatment with hydroxyurea. $\mathrm{Br} J$ Haematol. 1999;105(2):491-6.

24. Tripathi A, Jerrell JM, Stallworth JR. Clinical complications in severe pediatric sickle cell disease and the impact of hydroxyurea. Pediatr Blood Cancer. 2011;56(1):90-4.

25. Raffini $\sqcup$, et al. Prolongation of the prothrombin time and activated partial thromboplastin time in children with sickle cell disease. Pediatr Blood Cancer. 2006;47(5):589-93.

26. Chinawa JM, et al. Coagulation profile of children with sickle cell anemia in steady state and crisis attending the university of Nigeria teaching hospital, Ituku-Ozalla, Enugu. Niger J Clin Pract. 2013;16(2):159-63.
27. Bayazit AK, Kilinc Y. Natural coagulation inhibitors (protein C, protein S, antithrombin) in patients with sickle cell anemia in a steady state. Pediatr Int. 2001;43(6):592-6.

28. De Franceschi L, Cappellini MD, Olivieri O. Thrombosis and sickle cell disease. Semin Thromb Hemost. 2011;37(3):226-36.

29. Heller AR, et al. Impact of n-3 fatty acid supplemented parenteral nutrition on haemostasis patterns after major abdominal surgery. Br J Nutr. 2002; 87(Suppl 1):S95-101.

30. Vanschoonbeek $\mathrm{K}$, et al. Variable hypocoagulant effect of fish oil intake in humans: modulation of fibrinogen level and thrombin generation. Arterioscler Thromb Vasc Biol. 2004:24(9):1734-40.

31. Nieuwenhuys $C M$, et al. Vitamin K-dependent and vitamin K-independent hypocoagulant effects of dietary fish oil in rats. Thromb Res. 2001; 104(2):137-47.

32. Piccin $\mathrm{A}$, et al. Circulating microparticles, protein $\mathrm{C}$, free protein $\mathrm{S}$ and endothelial vascular markers in children with sickle cell anaemia. J Extracell Vesicles. 2015:4:28414

33. Hebbel RP, Vercellotti G, Nath KA. A systems biology consideration of the vasculopathy of sickle cell anemia: the need for multi-modality chemoprophylaxsis. Cardiovasc Hematol Disord Drug Targets. 2009;9(4):271-92.

34. Marlar RA, Kleiss AJ, Griffin JH. Mechanism of action of human activated protein C, a thrombin-dependent anticoagulant enzyme. Blood. 1982: 59(5):1067-72.

35. Koc A, Gumruk F, Gurgey A. The effect of hydroxyurea on the coagulation system in sickle cell anemia and beta-thalassemia intermedia patients: a preliminary study. Pediatr Hematol Oncol. 2003;20(6):429-34.

36. Ataga $\mathrm{Kl}$, et al. Association of coagulation activation with clinical complications in sickle cell disease. PLoS One. 2012;7(1):e29786.

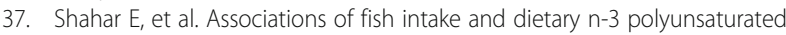
fatty acids with a hypocoagulable profile. The atherosclerosis risk in communities (ARIC) study. Arterioscler Thromb. 1993;13(8):1205-12.

38. Nomura S, Kanazawa S, Fukuhara S. Effects of eicosapentaenoic acid on platelet activation markers and cell adhesion molecules in hyperlipidemic patients with type 2 diabetes mellitus. J Diabetes Complicat. 2003;17(3):153-9.

39. Cottin SC, Sanders TA, Hall WL. The differential effects of EPA and DHA on cardiovascular risk factors. Proc Nutr Soc. 2011:1-17.

40. Woodman RJ, et al. Effects of purified eicosapentaenoic acid and docosahexaenoic acid on platelet, fibrinolytic and vascular function in hypertensive type 2 diabetic patients. Atherosclerosis. 2003;166(1):85-93.

41. Adan Y, et al. Effects of docosahexaenoic and eicosapentaenoic acid on lipid metabolism, eicosanoid production, platelet aggregation and atherosclerosis in hypercholesterolemic rats. Biosci Biotechnol Biochem. 1999;63(1):111-9.

42. Kollander R, et al. Nuclear factor-kappa B (NFkappaB) component p50 in blood mononuclear cells regulates endothelial tissue factor expression in sickle transgenic mice: implications for the coagulopathy of sickle cell disease. Transl Res. 2010;155(4):170-7.

43. Kalish BT, et al. Dietary omega-3 fatty acids protect against vasculopathy in a transgenic mouse model of sickle cell disease. Haematologica. 2015; 100(7):870-80.

44. Esmon CT. The interactions between inflammation and coagulation. $\mathrm{Br}$ J Haematol. 2005;131(4):417-30.

\section{Submit your next manuscript to BioMed Central and we will help you at every step:}

- We accept pre-submission inquiries

- Our selector tool helps you to find the most relevant journal

- We provide round the clock customer support

- Convenient online submission

- Thorough peer review

- Inclusion in PubMed and all major indexing services

- Maximum visibility for your research

Submit your manuscript at www.biomedcentral.com/submit 